\title{
Willingness of emergency department patients with musculoskeletal complaints to participate in complementary and alternative medicine research
}

\author{
Riyad B. Abu-Laban, MD, MHSc;* Catherina A. van Beek, RN, BSN;* \\ Jeffrey A. Quon, DC, FCCS(C), MHSc; † Joseph Wu, DSc, VP (MA), RAc
}

\begin{abstract}
Background: The emergency department (ED) is a unique potential location for recruitment into studies of complementary and alternative medicine (CAM) therapies. We sought to determine the stated willingness of ED patients with musculoskeletal complaints to participate in CAM research for their presenting problem, and to determine the characteristics of this population.

Methods: The study was carried out in the ED of Vancouver General Hospital weekdays between $10 \mathrm{am}$ and $6 \mathrm{pm}$ from Oct. 16, 2000, to Nov. 21, 2000. All adults who presented with musculoskeletal complaints involving the spine, upper extremity or lower extremity, unless they had pain severe enough to impair their ability to answer questions or unless there was a language or other communication barrier, were approached by a research nurse. If it was learned that they had already been assessed by an emergency physician, they were eliminated as potential study participants. After being presented background information by the research nurse, consenting patients were asked a series of standardized questions during a 15-minute private interview prior to their assessment by an emergency physician.

Results: Of 107 eligible patients, 93 participated (87\%). Most symptoms began on the day of presentation (44\%) or in the previous week (41\%). The mean age of those studied was 38 years, and $56 \%$ were male. Most presenting problems involved the ankle/foot (29\%), multiple sites (19\%), the lumbosacral region $(14 \%)$ or the wrist/hand $(14 \%)$. Seventy-six percent of patients had utilized CAM previously during their lives, and $13 \%$ were currently using CAM for their presenting problem. The majority of patients stated an informed hypothetical willingness to enroll in a CAM study of the following therapies: traditional Chinese medicine 74\% (69/93: 95\% confidence interval $[\mathrm{Cl}] 64.1 \%-82.7 \%)$; chiropractic $70 \%(65 / 93$ : $95 \% \mathrm{Cl} 59.5 \%-79.0 \%)$; and other CAM therapies $92 \%(86 / 93: 95 \% \mathrm{Cl} 85.1 \%-96.9 \%)$. Of patients asked, $99 \%$ stated they would comply with 4 to 6 weeks of outpatient follow-up, and $70 \%$ stated they would participate in a placebo-controlled study. Logistic regression modeling, performed for secondary purposes, indicated that willingness to participate in traditional Chinese medicine or chiropractic research was independent of age, sex, educational status, pain severity or prior exposure to the modality of interest.

Conclusions: ED patients with musculoskeletal complaints have a high stated willingness to participate in CAM research, even if this involves outpatient follow-up or a placebo-controlled design. ED-based CAM research appears feasible and should be pursued.
\end{abstract}

Key words: alternative medicine, chiropractic, emergency medicine, emergency care, emergency service, medicine traditional Chinese, musculoskeletal system, musculoskeletal abnormalities

\footnotetext{
From the *Department of Emergency Medicine, Vancouver General Hospital, Division of Emergency Medicine, University of British Columbia, Vancouver, BC; the †Cambie Chiropractic Centre, Vancouver, BC, and the TDepartment of Health Care and Epidemiology, University of British Columbia; and $¥$ The Integral Chinese Medicine and Acupuncture Research Foundation, Vancouver, BC
}

Received: May 24, 2002; final submission: Sept. 1, 2002; accepted: Sept. 4, 2002

This article has been peer reviewed. 


\begin{abstract}
RÉSUMÉ
Contexte : Le département d'urgence (DU) est un lieu de recrutement potentiel unique pour des études sur la médecine complémentaire et alternative. Nous avons tenté de déterminer la bonne volonté des patients vus à l'urgence pour des problèmes musculo-squelettiques à participer à une étude sur la médecine complémentaire et alternative pour le traitement de leurs symptômes et de déterminer les caractéristiques de cette clientèle.

Méthodes: L'étude fut menée au DU du Vancouver General Hospital sur semaine entre $10 \mathrm{~h}$ et $18 \mathrm{~h}$ du 16 octobre au 21 novembre 2000. Tous les adultes présentant des douleurs musculosquelettiques touchant la colonne vertébrale, les membres inférieurs et supérieurs furent abordés par une infirmière de recherche, à moins que leur niveau de douleur ne fût trop élevé ou qu'il y ait une barrière de communication linguistique ou autre. Après avoir été informés de la nature de la recherche, les patients consentants répondirent à une série de questions normalisées au cours d'une entrevue privée d'une durée de 15 minutes avant d'être vus par un médecin d'urgence.

Résultats : Parmi 107 patients admissibles, 93 (87\%) participèrent à l'entrevue. La plupart des symptômes s'étaient manifestés le jour de la visite au DU (44 \%) ou la semaine précédente (41\%). L'âge moyen des patients participant à l'étude était de 38 ans, $65 \%$ d'entre eux étant des hommes. La plupart des symptômes à la consultation touchaient la cheville/le pied (29\%), des sites multiples (19\%), la région lombo-sacrée (14\%) ou le poignet/la main (14\%). Soixante-seize pour cent des patients avaient eu recours à la médecine complémentaire et alternative auparavant et $13 \%$ y avaient recours pour leur problème actuel. La majorité des patients se dirent prêts à participer à une étude impliquant l'une des thérapies suivantes : médecine chinoise traditionnelle : $74 \%$ (69/93 : intervalle de confiance $95 \%$ [IC] 64,1\%-82,7\%); chiropratique : $70 \%$ (65/93 : IC $95 \% 59,5 \%-79 \%)$; et autres thérapies complémentaires : $92 \%$ (86/93 : IC $95 \%$ $85,1 \%-96,9 \%)$. Parmi les patients interrogés, $99 \%$ dirent être prêts à participer à 4 à six semaines de suivi en consultation externe et $70 \%$ dirent qu'ils participeraient à une étude placebo. La modélisation par régression logistique, effectuée à des fins secondaires, indiquait que la volonté des patients à participer à la recherche en médecine chinoise traditionnelle ou chiropratique était indépendante de l'âge, du sexe, du niveau d'éducation, de la sévérité de la douleur ou de I 'expérience antérieure avec la thérapie en question.

Conclusions: Les patients reçus à l'urgence pour des problèmes musculo-squelettiques manifestaient un intérêt élevé à participer à une recherche sur la médecine complémentaire, même si celle-ci impliquait un suivi en consultation externe ou une organisation à contrôle placebo. La recherche sur la médecine complémentaire et alternative basée au DU semble réalisable et devrait être approfondie.
\end{abstract}

\section{Introduction}

Complementary and alternative medicine (CAM) can be informally defined as any treatments, remedies or procedures not routinely prescribed by a conventional medical doctor, but which have been — or are currently being utilized for some sort of expected health benefit. Although culturally based, this definition is functional and consistent with those used in previous research. ${ }^{1-4}$

Over the last decade CAM has gained significant popularity throughout the industrialized world..$^{1-3,5-8}$ A United States population-based survey found a $25 \%$ increase in CAM use, a $47 \%$ increase in visits to CAM practitioners and a $45 \%$ increase in out-of-pocket expenditures for CAM services between 1990 and 1997. ${ }^{2}$ Canadian data show similar trends, ${ }^{4,8}$ and a 1997 study by the Fraser Institute reported $73 \%$ of Canadians had used at least one alternative therapy sometime in their lives. ${ }^{9}$ Studies that have specifically evaluated emergency department (ED) patients have found a similarly high prevalence of CAM usage in this population..$^{10-12}$ This has led to increasing support in Canada for the inclusion of CAM in medical education. ${ }^{13}$

One of the greatest controversies arising from the growth of CAM has been the degree to which these therapies have been subjected to scientific evaluation. Most health professionals believe there is an urgent need for rigorous studies on the safety and efficacy of many CAM therapies. In this regard, Health Canada recently allocated \$7 million to establish a new regulatory authority, the Directorate of Natural Health Products. ${ }^{14}$ Currently, only $\$ 1$ million annually from this office is dedicated to funding natural health product research. ${ }^{15}$ However, Canada's premier health research funding agency, the Canadian Institutes of Health Research, now includes "complementary and alternative care strategies" as a fundable domaine (www.cihr-irsc.gc.ca/institutes/ihspr/about_ihspr lihspr_about_institute_e.shtml; accessed 2002 Sept 10). 
The ED is a unique, and perhaps ideal, location to recruit subjects for CAM research studies, particularly those involving musculoskeletal complaints. Since many such patients present to the ED acutely following an injury, clinical trials evaluating the efficacy and safety of early-initiated CAM therapy may be possible. The willingness, however, of ED patients to participate in such research, and the previous CAM exposure and characteristics of those interested in participating, has never been established.

A Medline search from 1966 to present combining the terms "complementary therapies" or "alternative medicine" and "emergency department" or "emergency room" or "emergency medicine" failed to identify any ED-based clinical trials evaluating a CAM therapy. We felt that prior to embarking on an ED-based CAM study, the feasibility and projected enrollment of such research, with a particular focus on chiropractic and traditional Chinese medicine (TCM), required evaluation. Our interest in chiropractic and TCM arose from the areas of expertise within our study group and the widespread utilization of these two therapies for both acute and chronic musculoskeletal conditions. This study was designed to address the following 2 questions: 1) What proportion of ED patients with musculoskeletal complaints state a willingness to participate in CAM research for their presenting problem?; and 2) What are the demographic and other characteristics of this population?

\section{Methods}

\section{Design and location}

This prospective descriptive study was conducted in the ED of Vancouver General Hospital, Vancouver, BC. This tertiary trauma centre has an annual ED census of 53000 patients, $56 \%$ of whom are triaged to the treatment (nonurgent) area of the department.

\section{Ethics and approval}

The study was approved by the Behavioural Research Ethics Board of the University of British Columbia and by Vancouver Hospital and Health Sciences Centre. Written informed consent was obtained from all subjects prior to participation.

\section{Study setting and population}

From Oct. 16, 2002, to Nov. 21, 2000, sequential patients over age 16 who were triaged to the treatment area weekdays between $10 \mathrm{am}$ and $6 \mathrm{pm}$ were eligible if they presented with a musculoskeletal complaint involving any of the following locations: spine (cervical, thoracic, lumbosacral); upper extremity (shoulder/upper arm, elbow/forearm, wrist/hand); or lower extremity (hip/thigh, knee/lower leg, ankle/foot). Patients were excluded if they were unable to provide informed consent, had pain severe enough to impair their ability to answer questions, or if they had already been assessed by the emergency physician. A research nurse determined patient eligibility and documented any reasons for exclusion.

\section{Sample}

The times and days of study sampling were chosen to maximize patient enrollment during the period of high ED volume when research personnel are available. Based on projecting sufficiently narrow confidence intervals (CIs) for the proportion of subjects hypothetically willing to enroll in a CAM study ( $\pm 10 \%$ for an anticipated $50 \%$ enrollment), it was determined a priori that our minimum sample size requirement was 80 patients.

\section{Protocol and data collection}

One of 2 research nurses, dedicated to the study, was available each day during the study period and regularly reviewed the ED charts and computer tracking system for potentially eligible patients. In addition, triage and ED staff were trained to notify the research nurse of potentially eligible patients. All patients were approached by a research nurse and invited to participate in a standardized manner, after being triaged and prior to emergency physician assessment. All eligible patients were invited to participate. After being presented background information, consenting patients were asked a series of standardized questions by the research nurse during a 15 -minute interview in a private setting. The questions were closed-ended and addressed the following: demographics; details of presenting complaint; previous exposure to CAM; and hypothetical willingness to participate in modality-specific research (both within and outside of the ED) for the presenting complaint, assuming such studies had been available. To maintain consistency, written definitions of the following terms were read to subjects during the interview: complementary and alternative medicine; traditional Chinese medicine; and chiropractic (see Appendix 1). These definitions are not necessarily comprehensive, but were intended to summarize the experiences patients could expect to undergo in the context of future studies being considered within our department. Subjects were informed that TCM research would involve ED-initiated treatment followed by 5 weeks of outpatient therapy, and chiropractic research would involve either a single chiropractic treatment in the ED or a series of treatments administered over 4 weeks. Subjects were informed that research involving 
CAM therapies would occur simultaneously with standard medical care and at no additional patient cost. Responses were verbal and were recorded by the research nurse on a study form at the time of the interview and subsequently transferred to a computer database for analysis.

\section{Statistical analysis}

SPSS (version 6.1, Macintosh) was used to generate descriptive statistics and perform logistic regression modeling. Bionomial 95\% CIs for proportions, and tests of differences between proportions for exploratory purposes were calculated using Stata (Version 5.0, Macintosh). All statistical tests were 2-tailed and $p \leq 0.05$ was considered statistically significant.

\section{Results}

\section{Study population}

During the study period 1404 patients were seen in the ED. Of $749(53 \%)$ patients triaged to the treatment area, 150 (20\%) presented with a musculoskeletal complaint and 107 (71\%) of those patients met eligibility criteria (Fig. 1). Due to limitations in the computer registry system at the study site, the number of eligible patients presenting outside of the 10 am to $6 \mathrm{pm}$ window is not known. Eighty-seven percent of eligible patients consented to participate and these 93 patients comprise the study population.

The age of those studied ranged from 17 to 82, with a mean of 38 years. Fifty-six percent of subjects were male. The highest level of subjects' completed schooling was secondary school (51\%); a diploma program/community college (23\%); and a university degree (18\%). English was the primary language spoken at home for $77 \%$ of patients, and $66 \%$ spoke no second language. The mean length of stay in the ED was 167 minutes, and no subjects were admitted to hospital. Table 1 indicates the details of subjects' presenting complaint including onset, location, severity and cause. Table 2 indicates subjects' previous exposure to CAM. Seventy-six percent of patients had utilized CAM previously during their lives, and $13 \%$ were currently using CAM for their presenting problem.

\section{Willingness to participate in CAM research}

The majority of subjects stated an informed hypothetical willingness to enroll in a CAM study of the following therapies for their presenting complaint: TCM 74\% (69/93:

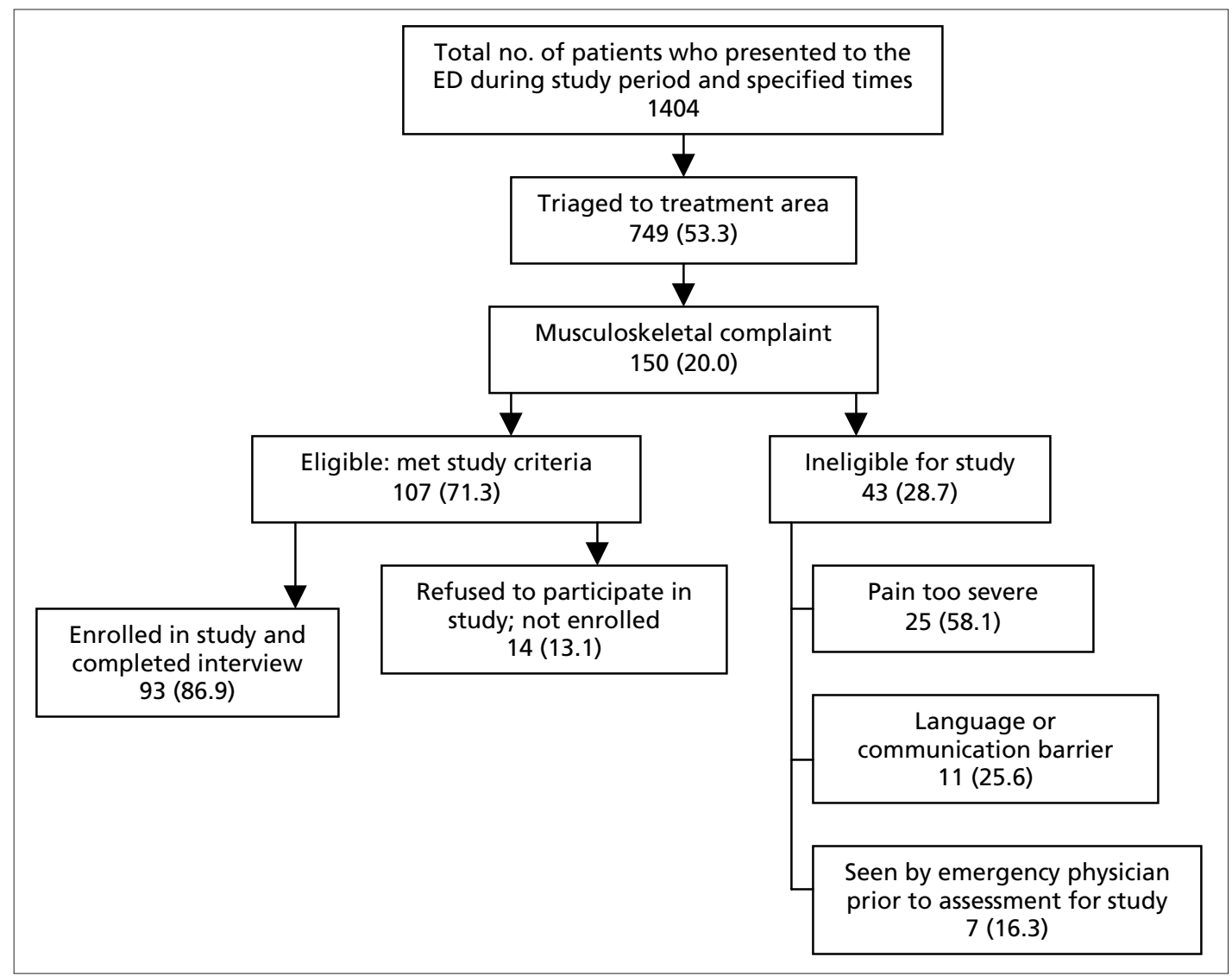

Fig. 1. Study population; no. (and \%) of patients in each category. ED = emergency department. 
95\%CI 64.1\%-82.7\%); chiropractic 70\% (65/93: 95\%CI $59.5 \%-79.0 \%)$; and other CAM therapies $92 \%$ (86/93: 95\% CI 85.1\%-96.9\%). The other CAM therapies that subjects were hypothetically willing to receive within a study setting included: massage (98\%); non-TCM acupuncture (65\%); homeopathy (48\%); and herbal remedies (54\%).

Of the subjects willing to enroll in a TCM or chiropractic study, $99 \%$ stated they were willing to comply with 4 to 6 weeks of outpatient follow-up. Of the 89 patients who indicated a willingness to participate in some form of research, $62(70 \%)$ stated they would participate in a placebo-controlled study. Logistic regression modeling was performed for secondary purposes and indicated that willingness to participate in TCM or chiropractic research was independent of age, sex, educational status, severity of pain or prior exposure to modality of interest.

\section{Discussion}

This study indicates that ED patients with musculoskeletal complaints have a high stated willingness to participate in

\section{Table 1. Details of presenting musculoskeletal complaint for patients enrolled in study}

\begin{tabular}{lc} 
Details of presenting complaint & No. (and \%)* \\
\hline Location of pain & \\
Cervical region & $4(4.3)$ \\
Thoracic region & $4(4.3)$ \\
Lumbosacral region & $13(14.0)$ \\
Shoulder / Upper arm & $2(2.2)$ \\
Elbow / Forearm & 0 \\
Wrist / Hand & $13(14.0)$ \\
Hip / Thigh & $1(1.1)$ \\
Knee / Lower leg & $11(11.8)$ \\
Ankle / Foot & $27(29.0)$ \\
More than one location & $18(19.4)$ \\
Time pain began & \\
Day of presentation to ED & $41(44.1)$ \\
1-7 d prior to presentation & $38(40.9)$ \\
8 d to 3 mo prior to presentation & $12(12.9)$ \\
More than 3 mo prior & $2(2.2)$ \\
Experienced same pain previously & $40(43.0)$ \\
Pain attributed to & \\
Motor vehicle collision & $14(15.1)$ \\
Injury sustained at work & $23(24.7)$ \\
Recreational activity & $14(15.1)$ \\
Other & $41(44.1)$ \\
Unknown & $1(1.1)$ \\
Verbal rating of pain by patient at time & \\
of presentation, mean (median)t & $6.7(7)$ \\
\hline$*$ Unless otherwise indicated & \\
+ Maximum score 10 & \\
\hline & \\
\hline & \\
\hline
\end{tabular}

CAM research, even if this involves outpatient follow-up or a placebo-controlled design. Seventy percent of subjects were willing to undergo a single chiropractic treatment for their presenting condition, $99 \%$ of whom would return for 8 treatment sessions over a 4-week period. Similarly, 74\% were willing to undergo TCM treatments up to twice weekly for a 5 -week period, $99 \%$ of whom would return for weekly research nurse follow up over 6 weeks.

These findings are consistent with the increasing North American interest in CAM; however, it is noteworthy that our analysis indicated that stated willingness to participate in CAM research was not dependent on previous exposure to CAM therapy. This suggests that ED-based studies on a "naïve" patient population (those with no prior experience with the modality of interest) would be feasible. It is well documented that in the general population CAM utilization is most prevalent among women, persons aged 25 to 49 , those

Table 2. Descriptions of patients' exposures to complementary and alternative medicine (CAM)

\begin{tabular}{|c|c|}
\hline Variable & $\begin{array}{l}\text { No. (and \%) } \\
\text { of patients }\end{array}$ \\
\hline \multicolumn{2}{|l|}{ Type of CAM practitioner(s) seen* } \\
\hline Chiropractor & $36(50.7)$ \\
\hline Massage therapist & $36(50.7)$ \\
\hline Acupuncturist (non TCM) & $13(18.3)$ \\
\hline Homeopath & $9(12.7)$ \\
\hline TCM practitioner & $8(11.3)$ \\
\hline Burn therapist & $1(1.4)$ \\
\hline Cranial sacral therapist & $1(1.4)$ \\
\hline Japanese style therapist & $1(1.4)$ \\
\hline Naturopath & $1(1.4)$ \\
\hline Ultrasound / Magnetic therapist & $1(1.4)$ \\
\hline No CAM practitioner seen & $3(4.2)$ \\
\hline Current or previous use of self- & $47(66.2)$ \\
\hline $\begin{array}{l}\text { First time use of CAM* } \\
\text { Less than } 1 \text { year ago } \\
\text { More than } 1 \text { year ago } \\
\text { Unknown }\end{array}$ & $\begin{array}{c}6(8.5) \\
63(88.7) \\
2(2.8)\end{array}$ \\
\hline $\begin{array}{l}\text { Most recent use of CAM* } \\
\text { Current } \\
\text { Less than } 6 \text { months ago } \\
6 \text { months to } 1 \text { year ago } \\
\text { More than } 1 \text { year ago } \\
\text { Unknown }\end{array}$ & $\begin{array}{l}21(29.6) \\
16(22.5) \\
10(14.1) \\
21(29.6) \\
3(4.2)\end{array}$ \\
\hline $\begin{array}{l}\text { Type(s) of CAM currently being } \\
\text { for presenting problemt } \\
\text { Herbal remedies (non TCM) } \\
\text { Chiropractic } \\
\text { TCM } \\
\text { Massage } \\
\text { Homeopathy }\end{array}$ & $\begin{array}{l}5(55.6) \\
3(33.3) \\
1(11.1) \\
1(11.1) \\
1(11.1)\end{array}$ \\
\hline \multicolumn{2}{|c|}{$\begin{array}{l}\text { TCM = traditional Chinese medicine } \\
* \text { for } 71 \text { patients }(76.3 \%) \text { who have used one or more CAM therapies } \\
+ \text { for } 9 \text { patients }(12.7 \%) \text { currently using one or more CAM therapies for } \\
\text { presenting problem }\end{array}$} \\
\hline
\end{tabular}


with higher education and income, and those with chronic conditions. ${ }^{1,2,4}$ In contrast, the characteristics of CAM users and hypothetical research participants in our ED study, drawn from a sample of predominantly acutely injured males of intermediate education, differ from these population-based correlates. Our regression analysis indicated that willingness to enroll in CAM studies was independent of age, sex, educational status, and severity of pain; thus, it would appear that enrollment of a representative sample of ED patients with musculoskeletal complaints into a CAM study could be done. Moreover, as symptoms began within 1 week of presentation to the ED for $85 \%$ of our sample population, the ED may be an ideal location for early intervention studies.

There are limitations that should be considered in the interpretation of our results. First, and most importantly, it merits mention that this was a study of stated willingness to enroll in a hypothetical study. While we could find no literature on this subject, it is conceivable that a patients' stated willingness to participate in CAM research may not translate into actual enrollment when a study is ongoing. It is likely that our findings represent a liberal estimate and that true enrollment would be lower than suggested from this study. This being said, the proportion of our study population that indicated an interest in CAM research was striking and suggests that ED-based clinical trials are feasible. We do not feel this stated interest arose from a poor understanding of what was involved in study participation because we were careful to provide subjects with detailed information to facilitate an informed decision. As subjects were interviewed prior to being assessed by the emergency physician, it is unknown whether interest in enrollment would be different after interaction with an emergency physician. It is possible that other factors influenced some subjects' stated willingness to participate in CAM research, such as the attractiveness of receiving CAM therapy at no cost or acquiescing to the presumed desires of the interviewer. We attempted to minimize these possibilities through the use of standardized closed-ended interview questions and objective data collection techniques.

Our findings suggest that ED-based studies of selected CAM modalities in patients with musculoskeletal complaints, particularly those with acute injuries, would be feasible from an enrollment perspective. As our ED is similar to most tertiary Canadian centres, we believe our results are generalizable to such locations. It is noteworthy that different CAM modalities would require different degrees of patient commitment and motivation. Compliance and logistical ease would likely be maximized by a study of a single ED-based intervention. Our intention is to develop and implement a CAM study in our ED, as we feel such research appears feasible and should be pursued.

\section{Competing interests: None declared.}

Acknowledgements: We thank our research nurses Ms. Susan Goguen and Ms. Andrea Ram. We also thank the emergency physicians and nurses of Vancouver General Hospital for their dedication to both excellence in patient care and research. Finally, we gratefully acknowledge the previous work of Dr. Anton Grunfeld, which led to the development of this study, and the support of Research Affairs at Vancouver Hospital and Health Sciences Centre.

Financial support for this study was provided through an interdisciplinary grant from the Vancouver Hospital/British Columbia Health Research Foundation Joint Hospital Community Research Partnership Competition (1999/2000). Dr. Riyad B. Abu-Laban is supported by a Scholar Award from the Michael Smith Foundation for Health Research. Dr. Jeffrey A. Quon is supported by a Postdoctoral Fellowship Partnership Award from the Canadian Institutes of Health Research, the Canadian Chiropractic Research Foundation and the BC College of Chiropractors, and a Doctoral Fellowship Award from the Michael Smith Foundation for Health Research.

\section{References}

1. Eisenberg D, Kessler R, Foster C, Norlock F, Calkins D, Delbanco T. Unconventional medicine in the United States: prevalence, costs, and patterns of use. N Engl J Med 1993;328:246-52.

2. Eisenberg D, Davis R, Ettner S, Appel S, Wilkey S, Van Rompay M, et al. Trends in alternative medicine use in the United States, 1990-1997. JAMA 1998;280:1569-75.

3. Kessler RC, Davis RB, Foster DF, Van Rompay MI, Walters EE, Wilkey SA, et al. Long-term trends in the use of complementary and alternative medical therapies in the United States. Ann Intern Med 2001;135:262-8.

4. Millar W. Use of alternative health care practitioners by Canadians. Can J Pub Health 1997;88:154-8.

5. Goldbeck-Wood S, Dorozynski A, Lie L, Yamauchi M, Zinn C, Josefson D, et al. Complementary medicine is booming worldwide. BMJ 1996;313:131-3.

6. Harris P, Rees R. The prevalence of complementary and alternative medicine use among the general population: a systematic review of the literature. Compl Ther Med 2000;88-96.

7. MacLennan A, Wilson D, Taylor A. Prevalence and cost of alternative medicine in Australia. Lancet 1996;347:569-73.

8. Verhoef M, Russell M, Love E. Alternative medicine use in rural Alberta. Can J Pub Health 1994;85:308-9.

9. The Fraser Institute. Alternative medicine in Canada: use and public attitudes. Fraser Institute Public Policy Source 21, 1999.

10. Gulla J, Singer A. Use of alternative therapies among emergency department patients. Ann Emerg Med 2000;35:226-8.

11. Allen R, Cushman LF, Morris S, Feldman J, Wade C, McMahon $\mathrm{D}$, et al. Use of complementary and alternative medicine among Dominican emergency department patients. Am J Emerg Med 2000;18:51-4.

12. Weiss S, Takakuwa K, Ernst A. Use, understanding, and beliefs about complementary and alternative medicines among emergency department patients. Acad Emerg Med 2001;8:41-7.

13. Verhoef MJ, Best A, Boon H. Role of complementary medicine in medical education: opinions of medical educators. Ann Roy Coll Phys Surg Can 2002;35:166-70.

14. Minister Rock accepts all 53 recommendations made in the Standing Committee report on natural health products, establishes new Office of Natural Health Products and announces funding for research [news release]. Health Canada; 1999 Mar 26. Available: www.hc-sc.gc.ca/hpb/onhp/rock_e.html (accessed 2002 Sept 10).

15. Smith M. Research in Complementary/Alternative Health Care (CAHC) and Natural Health Products (NHP) Canadian Institutes of Health Research (CIHR) Strategic Research Priorities Consensus Workshop. Toronto (ON): 2002 June 10. 
Correspondence to: Dr. Riyad B. Abu-Laban, Research Director, Department of Emergency Medicine, Vancouver General Hospital, 855 West 12th Ave., Vancouver BC V5Z 1M9; 604 875-4111 x62181, fax 604 875-4872, abulaban@interchange.ubc.ca

\section{Appendix 1. Definition of the terms "complementary and alternative medicine," "traditional Chinese medicine (TCM)" and "chiropractic," as read to potential study subjects during their interview with the research nurse}

\section{Complementary and alternative medicine}

Defined as "any treatments, remedies or procedures not routinely prescribed by a conventional medical doctor, but which have been - or are currently being — utilized for some sort of expected health benefit."

\section{Traditional Chinese medicine}

What is traditional Chinese medicine?

Traditional Chinese medicine involves the integration of an individualized traditional therapy plan for pain relief and the promotion of healing and includes the following treatment modalities.

- Pulse diagnosis and differentiation

- An assessment of the spinal shape and body structure

- Identification of the affected area(s)

- $\quad$ "Scraping" (stroking the skin surface using a spatula-like instrument) with mentholated ointment

- Massage with Chinese herbal cream and vitamin E lotion

- $\quad$ Spinal or joint adjustment (TCM style)

- Acupuncture (TCM style)

- $\quad$ Herbal pain patch (TCM style)

- Magnetic waist support

- Oral herbal medication (TCM style)

How long does traditional Chinese medicine treatment take?

Patients with mild to moderate pain usually receive 1 treatment per week. Patients with severe pain usually receive 2 treatments per week. Each treatment takes approximately 45 minutes. A treatment cycle consists of between 5 and 10 treatments, which translates into approximately 5 weeks of therapy.

\section{Chiropractic}

What is a chiropractor?

Chiropractors are health care practitioners who predominantly use their hands to examine and treat abnormalities of the body's alignment and function. Many chiropractors advise patients on how to avoid injury during regular activities at home, work and recreation. They also prescribe special exercise routines, and they sometimes rely on the use of electrical instruments to reduce pain and muscle tension (or spasm) over an injured body part.

\section{What is chiropractic treatment?}

The best known part of chiropractic treatment is manipulation, which is when the hands are used to push on the individual bones of the spine (and/or extremities) in an attempt to stretch muscles and joints that have become stiff and inflexible from previous injury or overuse. Gentle manipulation is extremely safe and painless, but often produces an audible "crack" or a "pop." This sound occasionally surprises a patient but simply indicates that a treated joint has successfully become unstuck. A variety of manipulation techniques not involving a "cracking" sound may also be used.

How long does chiropractic treatment take?

A typical chiropractic treatment session lasts 10 to 20 minutes (although first consultations may take longer). Usually, no more than 6 manipulations are given in a single appointment. Most neck and back injuries will best respond to a series of appointments administered over a 3- or 4-week period. However, even a single session may result in either long-term pain relief (especially if the injury is less than 7 days old), or at the very least, effective short-term relief for patients in need of symptomatic, emergency care. 